\title{
Novel popout is an attention-based phenomenon: An ERP analysis
}

\author{
DAVID L. STRAYER and WILLIAM A. JOHNSTON \\ University of Utah, Salt Lake City, Utah
}

\begin{abstract}
When observers are given a brief glimpse of a display containing one novel object and three repeated objects, they are often better able to report the location of the novel object than the location of any one of the repeated objects. The present study contrasted two interpretations of this "novel popout" effect. The attention-based interpretation suggests that the novel popout is an attentional phenomenon, occurring during the initial processing of the four-object display. The retrieval-based interpretation suggests that novel popout is due to differential processing occurring when observers are subsequently probed for the location of one of the objects in the display. ERP measures recorded while subjects performed the novel popout task revealed differences during the initial processing of the four-object display but not subsequent to the presentation of a localization probe. The findings are most consistent with the attention-based interpretation of novel popout, which suggests that attention is rapidly drawn to the novel object in an otherwise familiar display.
\end{abstract}

The adaptive organism must strike an appropriate balance between mental stability and mental flexibility. Mental stability is evidenced by the voluminous literature on cognitive biases toward familiar and expected inputs. Mental flexibility is evidenced by the less voluminous literature on cognitive biases toward novel and unexpected inputs (for a review, see Johnston \& Hawley, 1994). Thus, natural selection has managed to design mind/brain systems that are biased simultaneously toward expected and unexpected inputs. In the present study, we exploited a paradigm called novel popout to examine how the mind/ brain system accomplishes this impressive feat.

Unlike various data-driven forms of "attention capture," novel popout is conceptually driven, being produced by novel or unexpected, but physically inconspicuous, intrusions into familiar fields. On a typical trial, observers are given a brief glimpse of a four-object array (called the attention array) and are subsequently probed for the location of one of the objects. Some objects (called $f a-$ miliar) appear many times across trials; others (called novel) appear only once. The standard design includes three compositions or types of array: all-novel, in which only novel objects appear; all-familiar, in which only familiar objects appear; and one-novel, in which a single novel object appears in a field of three familiar objects. The typical pattern of results includes three basic effects: baseline, novel popout, and familiar sink-in. The baseline effect is defined by higher accuracy of localization for

The authors thank Irene Schwarting for assisting in the collection of these data and Steve Luck, Ray Klein, and Tram Neil for comments on an earlier version of this manuscript. Correspondence should be addressed to D. L. Strayer, Department of Psychology, University of Utah, 390 South 1530 East, Room 502, Salt Lake City, UT 84112-0251 (e-mail: strayer@psych.utah.edu). all-familiar arrays than for all-novel arrays. This effect exemplifies mental stability - that is, the bias toward expected inputs. The novel popout effect is defined by the higher accuracy of localization for novel objects in onenovel arrays than for those in all-novel arrays. The familiar sink-in effect is defined by the lower accuracy for the familiar objects in one-novel arrays than for those in all-familiar arrays. Novel popout and familiar sink-in are sometimes of sufficient magnitude that the novel "singletons" are more localizable than familiar field objects in one-novel arrays. These popout and sink-in effects exemplify mental flexibility-that is, the bias toward unexpected inputs.

Johnston and colleagues (Hawley, Johnston, \& Farnham 1993; Johnston \& Hawley, 1994; Johnston, Hawley, \& Farnham, 1993; Johnston, Hawley, Plewe, Elliott, \& DeWitt, 1990; Johnston \& Schwarting, 1997; Johnston, Schwarting, \& Hawley, 1996) have suggested that novel popout is a conceptually driven form of attention capture. Evidence that attention is drawn automatically to novel singletons comes from observations that novel popout holds up with exposure durations as brief as $33 \mathrm{msec}$ and is insensitive to strategic manipulations such as speedaccuracy tradeoffs and explicit search strategies. Although these results are consistent with the hypothesis that novel popout is a form of attention capture, the postcue probe procedure used in the paradigm allows the possibility that it may arise during the processing of the localization probe rather than the attention array itself.

In their critique of the novel popout paradigm, Christie and Klein (1996) noted that

an effect on accuracy of identity localization that is measured between 0.5 and $1 \mathrm{~s}$ after the presentation of an array can be mediated by processes operating during any combination of encoding, storage, and retrieval of the array information. This [novel popout] effect certainly can- 
not be used to make claims about attentional shifts any specific time prior to the time of the probe. (p. 206)

For example, one retrieval-based possibility is that observers may notice a "perceptual trouble spot" in the array and, when a novel item is presented as the probe, accurately guess that it was in the trouble spot. In general, because the novel popout paradigm uses a postcuing paradigm, measures of accuracy could reflect differential processing during the attention array, during the probe array, or both. An on-line measure of processing during the task might help to discriminate between these possibilities by indicating when differential processing occurs. The event-related brain potential (ERP) methodology may provide such an on-line measure of processing.

The ERP is a transient series of voltage oscillations in the brain that can be recorded in response to the occurrence of a discrete event (Donchin, Ritter, \& McCallum, 1978). In the present study, subjects performed a standard novel popout task while electroencephalographic (EEG) activity was simultaneously recorded from scalp electrodes. ERPs were generated by averaging the EEG signals for each of the array types (all-familiar, one-novel, and all-novel). If ERPs are sensitive to the processing underlying novel popout, then they may be used to temporally localize this processing. For example, if novel popout is an attention-based phenomenon, then the different types of attention array may elicit different ERPs before the presentation of the probe array. However, if novel popout is a retrieval-based phenomenon, then ERP differences may not be observed until the localization probe has been presented. In short, the ERP methodology may provide a unique opportunity to assess the processing loci of novel popout.

To anticipate, there is good reason to suspect the ERP data, especially the N400 component, to illuminate the basis of novel popout. The $\mathrm{N} 400$ is a negative potential in the ERP, peaking at approximately $400 \mathrm{msec}$ after stimulus onset. Studies examining ERPs elicited in priming paradigms have found that the $\mathrm{N} 400$ is smaller for words that have been recently primed than for nonprimed words (e.g., Bentin \& McCarthy, 1994; Rugg, 1985). In addition, Rugg (1985) has shown that the N400 is greatly attenuated when words are repeated. These findings suggest that the $\mathrm{N} 400$ can be used as an index of the processing of novelty in the novel popout task.

\section{METHOD}

\section{Subjects}

The subjects were 32 undergraduates from the University of Utah. They were between the ages of 18 and 25 years, had normal or corrected-to-normal vision, were native speakers of English, and were right-handed.

\section{Stimuli and Apparatus}

The stimuli were 1,300 four- to seven-letter words ( 325 of each word length) from the Kučera and Francis (1967) word norms. Word frequencies ranged between 18 and 32 per million. The experiment was controlled with an IBM-compatible 486 computer. Stimuli were presented on a NEC superVGA display. The subjects indicated their responses via a four-button response box.

\section{Procedure}

On each trial, an attention array consisting of four words (one of each word length) was presented for $200 \mathrm{msec}$. The attention array was immediately followed by a backward mask, which was presented for $100 \mathrm{msec}$. Five hundred milliseconds after the backward mask, one of the words was presented in the center of the display as the probe, and the subject's task was to indicate the location that the probe word had occupied in the attention array by pressing the corresponding button on the response box. After the response, accuracy feedback in the form of an asterisk presented in the correct location was provided for $500 \mathrm{msec}$. Following a $200-\mathrm{msec}$ interval, the next trial began.

There were three types of attention array: all-familiar, all-novel, and one-novel. All-familiar arrays consisted of four words that appeared together many times in the experiment. All-novel arrays consisted of four experimentally novel words. One-novel arrays consisted of three of the familiar words and one experimentally novel word. The experiment began with 48 prefamiliarization trials, in which the four familiar words were presented in all possible spatial configurations. The remainder of the experiment consisted of 96 all-familiar trials, 96 all-novel trials, and 384 one-novel trials presented in an unpredictable order. On all-familiar trials, each familiar word was probed equally often from each of the four array locations. On all-novel trials, each location and word length was probed equally often. On one-novel trials, one of the familiar words was replaced with an experimentally novel word of equal length, ensuring that the novel singleton was not aberrant in length and did not create an unusual pattern of word length. Each location and word length was probed equally often. Thus, the novel singleton was probed on a total of $25 \%$ of the trials.

Following the novel popout task, the subjects performed a 5-min $80 / 20$ visual oddball task in which they counted the number of lowercase words $(20 \%)$ in a series of uppercase and lowercase words. The oddball task was used only to facilitate identification of the components within the ERP waveform and will not be discussed further.

\section{EEG Recording and Data Analysis}

EEG activity was recorded from three midline sites $(\mathrm{Fz}, \mathrm{Cz}$, and $\mathrm{Pz}$, according to the international 10-20 system; Jasper, 1958) and referred to linked mastoids. Bipolar vertical electrooculographic (EOG) activity was simultaneously recorded to ensure that eye movements did not contaminate the EEG records. MED 10-mm-diameter Ag/ $\mathrm{AgCl}$ biopotential electrodes were used at all electrode sites, and electrode impedance did not exceed $10 \mathrm{k} \Omega$.

EEG and EOG signals were amplified with a Grass Model 12 Neurodata Acquisition System. Both EEG and EOG were sampled every $5 \mathrm{msec}$ for $2,000 \mathrm{msec}$, beginning $200 \mathrm{msec}$ prior to the attention array onset. The digitized data were stored on disk for subsequent analysis. EOG artifacts were corrected off line with a procedure described by Gratton, Coles, and Donchin (1983).

\section{RESULTS}

As Table 1 reveals, the accuracy data for each of the array/probe type conditions replicate the basic pattern of effects reported by Johnston and colleagues (Johnston \& Hawley, 1994; Johnston et al., 1993; Johnston et al., 1990; Johnston \& Schwarting, 1997). One-tailed $t$ tests indicated statistical reliability for the baseline effect, defined by the higher accuracy of localization for all-familiar arrays than for all-novel arrays $[t(31)=4.75, p<.01]$; the 
Table 1

Accuracy Means and Standard Deviations

for Each of the Array/Probe Conditions

\begin{tabular}{lccccc}
\hline & \multicolumn{4}{c}{ Probe } \\
\cline { 2 - 5 } Array & \multicolumn{3}{c}{ Familiar } & & Novel \\
\cline { 2 - 5 } Condition & $M$ & $S D$ & & $M$ & $S D$ \\
\hline All-Familiar & 67.9 & 7.9 & - & - \\
All-Novel & - & - & 62.2 & 8.7 \\
One-Novel & 66.5 & 7.3 & 69.1 & 8.1 \\
\hline
\end{tabular}

between-arrays novel popout effect, defined by the higher localization accuracy for novel words in one-novel arrays than for those in all-novel arrays $[t(31)=6.39, p<$ $.01]$; the between-arrays familiar sink-in effect, defined by the lower localization accuracy for the familiar words in one-novel arrays than for those in all-familiar arrays $[t(31)=1.8, p<.05]$; and the within-array novel popout effect, defined by higher localization accuracy for novel words than for familiar words in one-novel arrays $[t(31)=$ $2.68, p<.01]$.

Figure 1 presents the average ERPs from trials associated with correct localizations. Inspection of the waveforms indicates that the attention array elicited an initial positivity with a peak latency of approximately $200 \mathrm{msec}$, a negativity with a peak latency of approximately $400 \mathrm{msec}$, and a later positivity with a peak latency of approximately $550 \mathrm{msec}$. The localization probe elicited a negativity with a peak latency of approximately $100 \mathrm{msec}$ (postlocation probe onset) and a positivity with a peak latency of approximately $500 \mathrm{msec}$ (postlocation probe onset). Further inspection of the waveforms indicates that the N400 elicited by the attention array varied as a function of both electrode site and type of attention array. Whereas these differences between array types were maximal at the peak latency of approximately $400 \mathrm{msec}$, they began to emerge before the termination of the attention array.

The analyses of the ERP waveforms were structured in the following manner. We first examined the ERPs elicited by the attention array to determine whether there were differences in processing as a function of array type. Differences in processing occurring during this interval would be consistent with the attention-based interpretation of novel popout. These ERP differences would be most compelling if they were correlated with subsequent localization performance. Second, we examined the ERPs elicited by the localization probe to determine whether they varied as a function of array type. Differences in processing occurring during this interval would be consistent with the retrieval-based interpretation of novel popout, particularly if there were no ERP differences observed during the processing of the attention array. To anticipate our findings, early differences in the processing of the attention array that are related to subsequent localization performance, coupled with an absence of differences in the ERPs elicited by the localization probe, would constitute support for the attention-based interpretation of novel popout.

\section{Attention-Array ERPs}

An analysis of the N400s elicited by the attention array confirmed the visual inspection of the data. The amplitude of the N400 was computed by integrating the area between 250 and $550 \mathrm{msec}$. A 3 (electrode: Fz, Cz, and $\mathrm{Pz}$ ) $\times 3$ (array type: all-familiar, one-novel, and allnovel) repeated measures analysis of variance (ANOVA) revealed that the $\mathrm{N} 400$ increased in amplitude from frontal to parietal electrode sites $\left[F(2,62)=106.9, M S_{\mathrm{e}}=14,698\right.$, $p<.01]$ and was larger for all-novel arrays than for onenovel arrays and for one-novel arrays than for all-familiar arrays $\left[F(2,62)=25.8, M S_{\mathrm{e}}=6,477, p<.01\right]$. These two factors interacted $\left[F(4,124)=14.8, M S_{\mathrm{e}}=863, p<\right.$ $.01]$, indicating that the effect of type of attention array was greatest at the parietal electrode site.

The evidence indicates that differential processing of novel singletons was elicited by the attention arrays themselves. However, some researchers might attempt to account for these data by appealing to the the well-established finding that the $\mathrm{N} 400$ is generally smaller for primed (i.e., familiar) words than for nonprimed (i.e., novel) words (e.g., Rugg, 1985). We now turn to a series of additional analyses that were performed to provide further support for the interpretation that the novel singleton is processed at the expense of the familiar field items.

To more clearly determine when the difference between attention array conditions emerged, Figure 2 presents the standardized ( $t$-score) differences between the all-familiar arrays and both the one-novel (dotted line) and the allnovel (dashed line) arrays. Relative to the all-familiar condition, a large negativity with a peak latency of $400 \mathrm{msec}$ is clearly identifiable. The difference waveforms began to diverge as a function of array type within $70 \mathrm{msec}$ of the presentation of the attention array and became statistically reliable at $200 \mathrm{msec}$ for the one-novel array and $215 \mathrm{msec}$ for the all-novel array. These difference waveforms suggest that processing of the novelty began sometime within the $70-200-\mathrm{msec}$ window. It is noteworthy that the processing of the novel singleton appears to have begun at the same time, if not slightly before, processing of novelty in an all-novel array. Note that the first (and only) words to be processed in all-novel arrays were novel words, whereas this was not necessarily the case in onenovel arrays. Thus, the early onset of the N400 for onenovel arrays indicates that the novel singleton was as rapidly processed as the first item processed in an allnovel array.

In order to relate ERP activity more specifically to the novel popout effect, we examined separately the ERPs elicited by the attention array on one-novel trials in which the subjects were subsequently correct or made errors in localization. Trials were also separated on the basis of whether the novel item or one of the familiar items was probed. The rationale underlying these conditional accuracy analyses is as follows. If the N400 effects are related to the processing of the novel singleton, then the N400 should be larger when subjects subsequently correctly localize the novel singleton, indicating that they 


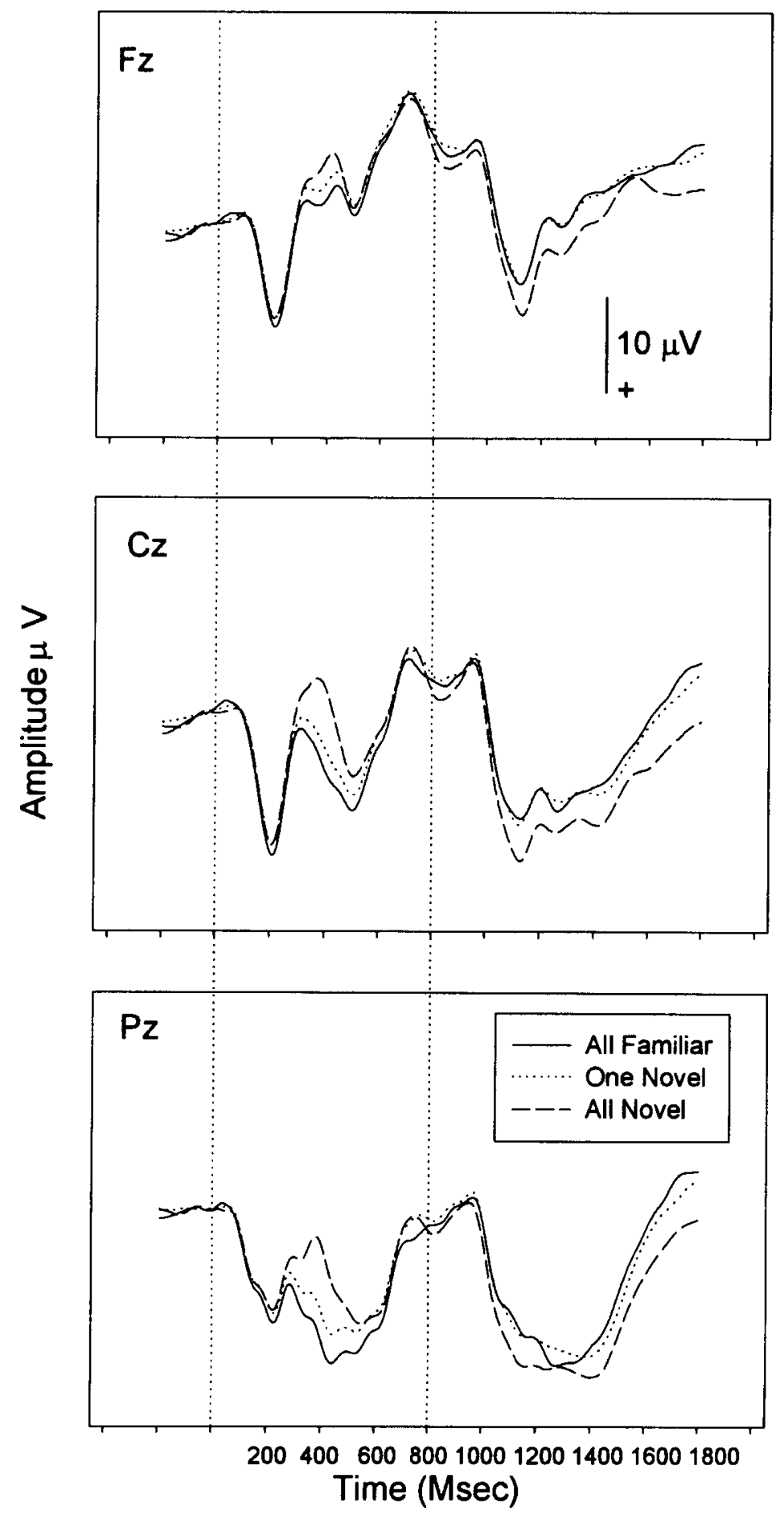

Figure 1. Average ERPs from correctly localized trials in the novel popout task. The top panel presents the recordings from the frontal $(\mathrm{Fz})$ electrode; the middle panel presents the recordings from the central $(\mathrm{Cz})$ electrode; and the bottom panel presents the recordings from the parietal $(\mathrm{Pz})$ electrode. The solid line represents the all-familiar condition; the dotted line represents the onenovel condition; the dashed line represents the all-novel condition. Vertical lines at 0 and 800 msec indicate the onset of the attention array and localization probe, respectively. 


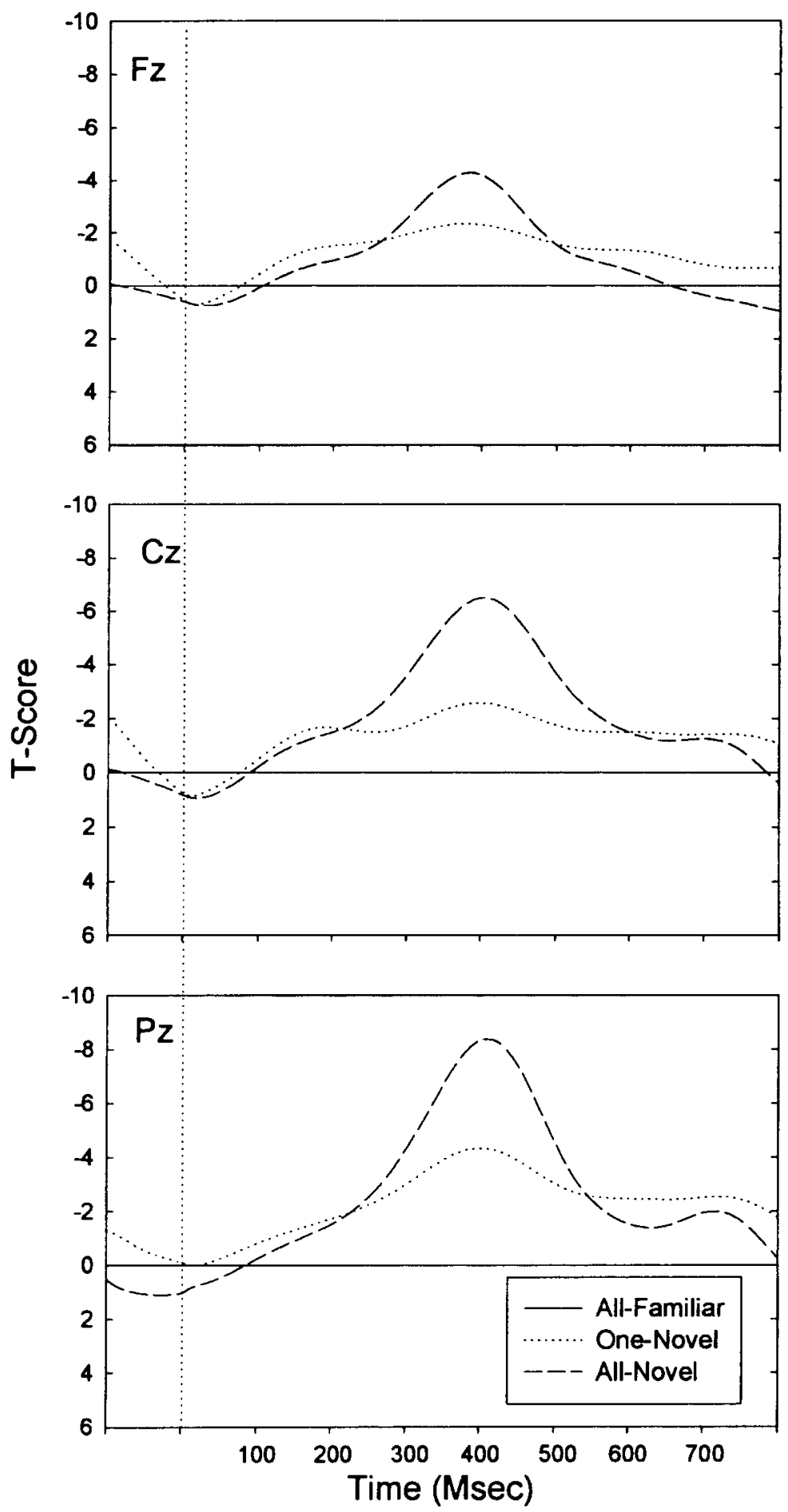

Figure 2. Average difference waveforms derived by subtracting the all-familiar ERP from the ERP for each condition. Deviation scores that exceed $t(31)=1.68$ are significant at $p<.05$ (one-tailed test). The top panel presents the recordings from the frontal $(\mathrm{Fz})$ electrode; the middle panel presents the recordings from the central $(\mathrm{Cz})$ electrode; and the bottom panel presents the recordings from the parietal $(\mathrm{Pz})$ electrode. The dotted line represents the one-novel condition; the dashed line represents the all-novel condition. The vertical line at $0 \mathrm{msec}$ indicates the onset of the attention. 
attended to it, than when they incorrectly localize it, indicating that they did not attend to it. The enhancement of the $\mathrm{N} 400$ on correct trials would be a manifestation of novel popout. Moreover, the N400 elicited by a one-novel array should be larger when subjects subsequently incorrectly localize familiar probes, indicating that they attended to the novel singleton, than when they correctly localize them, indicating that they did not attend to the novel singleton. The later ERP difference would be a manifestation of familiar sink-in. Together, these patterns would indicate that the novel item was processed at the expense of the familiar items in one-novel arrays.

Figure 3 presents the ERP waveforms associated with these various contingencies on one- novel trials. Trials in which the novel singleton was probed are presented in the top panel, and trials in which the location of one of the familiar items was probed are presented in the bottom panel. Correct trials are indicated by solid lines, and incorrect trials are indicated by dotted lines. The top panel indicates that the $\mathrm{N} 400$ was larger when the novel item: were correctly localized than when they were incorrectly localized. In contrast, the bottom panel reveals that the N400 was larger when the familiar items were incorrectly localized than when they were correctly localized. These differences were confirmed by a 2 (novel vs. familiar item probed) $\times 2$ (correct vs. incorrect localization) repeated measures ANOVA of N400 amplitude. The ANOVA revealed that N400 amplitude was greater for novel items than for familiar items $[F(1,31)=7.3$, $\left.M S_{\mathrm{e}}=3,317, p<.01\right]$. In addition, the $\mathrm{N} 400$ was greater for correct trials than for error trials when the novel item was probed and greater for error trials than for correct trials when the familiar item was probed $[F(1,31)=6.8$, $\left.M S_{\mathrm{e}}=3,842, p<.01\right]$. By contrast, a comparable analysis performed on all-novel and all-familiar trials found that the N400 was greater for novel trials than for famil-

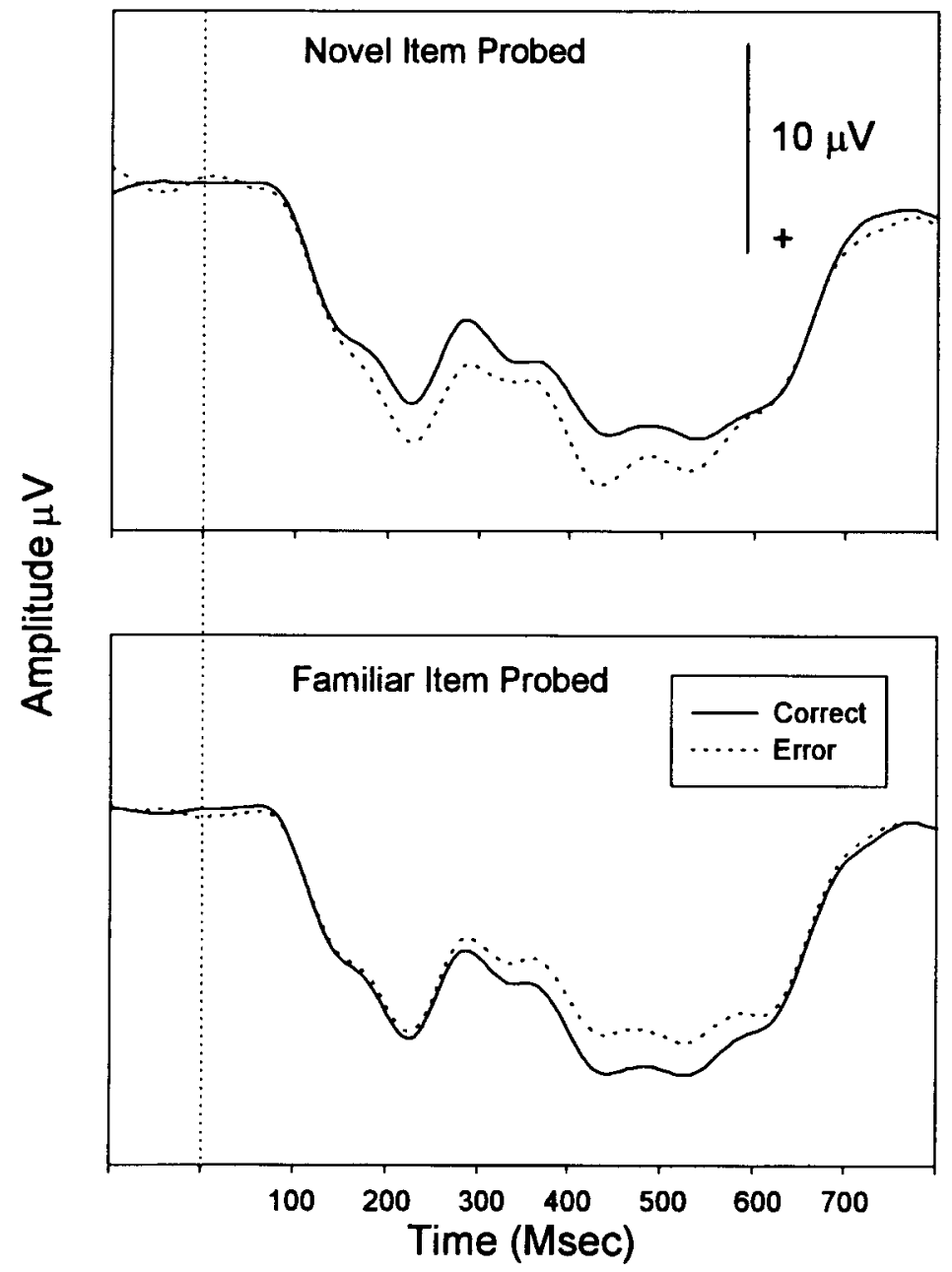

Figure 3. Average ERPs recorded from the parietal (Pz) electrode elicited by one-novel trials. The top panel presents trials in which the novel singleton was probed; the bottom panel presents trials in which one of the familiar items was probed. Correct trials are indicated by the solid line; incorrect trials are indicated by the dotted line. The vertical line at 0 msec indicates the onset of the attention array. 
iar trials $\left[F(1,31)=92.6, M S_{\mathrm{e}}=3,815, p<.01\right]$ but that this effect was not modulated by localization accuracy $(p>.75)$.

The conditional accuracy analyses are important because they demonstrate that the N400 effects are not simply the result of probe type (i.e., familiar vs. novel) or localization accuracy (i.e., correct vs. incorrect). The N400 differences cannot be due solely to the type of probe, because, on one-novel trials, subjects could not know in advance whether the familiar item or the novel item would be probed. The N400 differences cannot be due to making correct or incorrect responses on one-novel trials, because the pattern reverses depending on whether a familiar item or a novel item is probed. In addition, the interaction of probe type and localization accuracy was not obtained with all-familiar and all-novel trials. Instead, the N400 is modulated by localization accuracy only in one-novel conditions. Given that the $\mathrm{N} 400$ provides an index of the processing of the novel item, then these data suggest that the novel item was processed at the expense of the familiar items.

\section{Localization Probe ERPs}

To assess the possibility that the ERPs might also be affected by processing elicited by the localization probe, we sorted one-novel trials on the basis of whether the novel singleton or one of the familiar items was probed. Figure 4 presents the probe array ERPs for these trials, along with the corresponding ERPs for all-novel and allfamiliar trials. Figure 4 reveals a broad positive component in the ERP, with a maximal amplitude at parietal electrode sites and a peak latency ranging from 300 to $700 \mathrm{msec}$. On the basis of scalp distribution, peak latency, and similarity with ERPs elicited in the oddball task, we identify this as the P300 component of the ERP (cf. Fabiani, Gratton, Karis, \& Donchin, 1988). Inspection of Figure 4 indicates only a general trend toward larger P300 amplitudes for all-novel probes than for other probes and no systematic differences among the other probes.

Because the peak latency of the P300 is sensitive to variability in stimulus evaluation processes (e.g., Kutas, McCarthy, \& Donchin, 1977; Magliero, Bashore, Coles, \& Donchin, 1984; McCarthy \& Donchin, 1981), the P300 average waveforms may distort true differences in latency and amplitude. For example, a condition with greater variability in processing may appear to have a smaller amplitude than a condition with lesser variability when, in fact, both have equivalent amplitudes. To compensate for this latency jitter, we estimated the peak latency of the P300 on each trial using a standard peak picking algorithm (Fabiani et al., 1988) and then submitted these latency and amplitude estimates to separate repeated measures ANOVAs for statistical assessment. As can be seen in Table 2, there were no reliable differences in P300 latency between conditions (all $p s>.15$ ). Also presented in Table 2 are the P300 amplitude data. The only reliable effect on P300 amplitude was an enhancement of the P300 on all-novel trials relative to the other conditions $\left[F(3,93)=11.3, M S_{\mathrm{e}}=3.8, p<.01\right]$. Importantly, neither P300 latency nor amplitude differed between the novel and familiar probes that followed one-novel arrays. Because we corrected for latency jitter on a single-trial

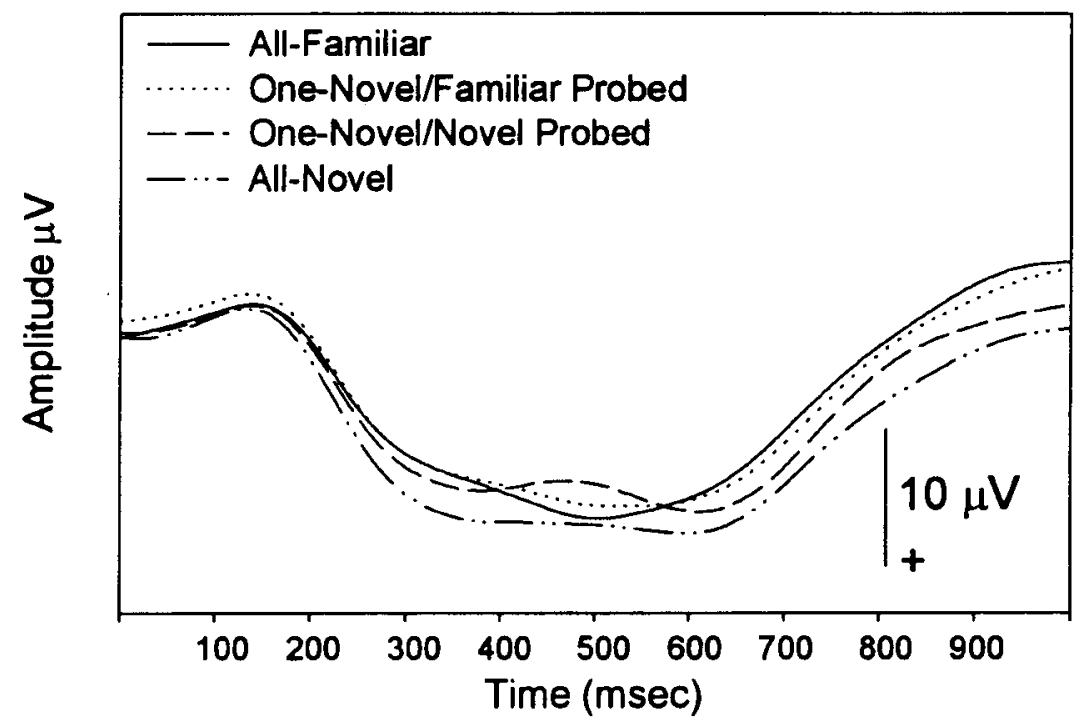

Figure 4. Average ERPs recorded from the parietal (Pz) electrode elicited by the localization probe. The solid line represents the all-familiar condition; the dashed-dotted line represents the all-novel condition. One-novel trials in which the novel singleton was probed are represented by the dashed line; one-novel trials in which one of the familiar items was probed are represented by the dotted line. 
Table 2

P300 Latency and Amplitude Means and Standard Deviations for Each of the Array/Probe Conditions

\begin{tabular}{lccccc}
\hline & \multicolumn{5}{c}{ Probe } \\
\cline { 2 - 3 } \cline { 5 - 5 } Array & \multicolumn{3}{c}{ Familiar } & & Novel \\
\cline { 2 - 3 } \cline { 5 - 6 } & $M$ & $S D$ & & $M$ & $S D$ \\
\hline All-Familiar & 509 & 37 & & \\
All-Novel & - & - & 521 & 50 \\
One-Novel & 519 & 37 & 522 & 40 \\
& P300 Amplitude & & \\
All-Familiar & 25.5 & 6.6 & - & - \\
All-Novel & - & - & 26.2 & 6.8 \\
One-Novel & 25.5 & 6.7 & 27.9 & 6.2 \\
\hline
\end{tabular}

Note-P300 latency is expressed in milliseconds, and P300 amplitude is expressed in microvolts.

basis, the absence of ERP differences elicited during the processing of the localization probe cannot be attributed to differences in the variability of processing.

Taken together, the results support the attention-based interpretation of novel popout and are inconsistent with the retrieval-based interpretation. Specifically, the ERP data indicate (1) that there were relatively early (i.e., $<200 \mathrm{msec}$ ) differences in processing elicited by the different types of attention array, (2) that the N400 differences on one-novel trials reflected selective processing of the novel singletons, and (3) that there were no ERP differences as a function of array type elicited by the localization probe.

\section{DISCUSSION}

In the present study, we contrasted two broad classes of interpretations of novel popout. The first class suggests that novel popout is an attention-based phenomenon, arising from the initial processing of the attention array. The second class suggests that novel popout is due to some differential processing occasioned by the localization probes. The ERP measures indicated differential N400 processing during the one-novel attention arrays that was related to subsequent localization performance. There were no ERP differences elicited by the localization probe in the critical one-novel condition. This pattern of data is most consistent with attention-based interpretations of novel popout.

Several points concerning the results are noteworthy. First, in contrast to Christie and Klein's (1996, p. 207) conclusion that "the within-array advantage for novel items is rare ... and the methods used to produce it are often compromised," we found reliable within-array novel popout in accuracy measures when there were no confounds in the experimental design (see also Diliberto, Altarriba, \& Neill, 1998, Experiment 1; Johnston \& Schwarting, 1997, Experiment 2).

Second, N400 differences emerged shortly after the presentation of the attention array. Thus, the ERP response to novel singletons occurs relatively early in the information processing sequence. The $\mathrm{N} 400$ differences began to emerge within $70 \mathrm{msec}$ and became statistically reliable within $200 \mathrm{msec}$ of the onset of the attention array. By comparison, some of the earliest patterns of activation produced in primary visual cortex do not begin until about $50 \mathrm{msec}$ after stimulus onset, suggesting an early detection of the novel singleton (e.g., Hillyard, Mangun, Woldorff, \& Luck, 1995). Furthermore, the detection of novelty in one-novel arrays, as indexed by the N400, became statistically reliable even before the processing of novelty in all-novel arrays. The latter finding suggests that the novel singleton receives some sort of prioritization in processing. Taken together, the N400 data suggest that the novel singleton was processed relatively early in the information processing stream.

A third point is that these $\mathrm{N} 400$ differences were related to subsequent localization performance. On one-novel trials in which the subjects were probed for the novel singleton, the N400 was greater on correct trials than on error trials. Likewise, on one-novel trials in which the subjects were subsequently probed for the location of one of the familiar items, the $\mathrm{N} 400$ was greater on error trials than on correct trials. Thus, N400 appears to have been elicited primarily on the very one-novel trials on which the observed novel popout and familiar sink-in effects on localization accuracy were based.

A fourth point is that a larger N400 does not necessarily imply "better processing"; rather, it is a signature of the processing of novel items. For example, the N400 is greater for all-novel arrays than for all-familiar arrays even though accuracy is higher in the latter condition (defining the baseline effect). In addition, the $\mathrm{N} 400$ on onenovel trials is larger when subjects make errors to familiar probes than when they are correct and this pattern is reversed if the novel singleton is probed.

Fifth, in conjunction with prior findings, our ERP data imply that novel popout is based on the semantic processing of novel singletons. In the ERP literature, large N400s are elicited by both words and phonologically legal nonwords (Bentin, 1987), whereas N400s are absent from ERPs elicited by orthographically and phonologically illegal nonwords (Nagy \& Rugg, 1989). This modulation of the N400 has led to the conclusion that the N400 is a manifestation of processes underlying access to semantic memory (e.g., Bentin \& McCarthy, 1994). Because semantic analysis is thought to be preceded by lexical/ identification processes, our N400 data imply that the identities of the novel singletons were processed in onenovel arrays. If this were not the case, then the N400 should be absent from the ERPs elicited by these singletons.

Finally, we should note that just because there were no differences in the ERP elicited by the localization probe on one-novel trials, it does not necessarily imply that there were no processing differences in this time frame. It is always possible that the ERP was not sensitive to these processing differences. Nevertheless, the $\mathrm{N} 400$ conditional accuracy differences elicited by the attention array would have provided strong evidence for attention-based inter- 
pretations of novel popout even if there were differences in the ERP elicited by the localization probe. This follows because differences in the nature of processing occurring during the attention array could potentially affect the representations on which the processes elicited by the localization probe operate.

In general, the data indicate that novel popout is based on the selective perceptual processing of novel singletons in one-novel arrays. Independent evidence for an attention-capture interpretation of novel popout has recently been reported by Diliberto, Altarriba, and Neill (1997). These investigators observed that accuracy of localization of a single bright word in a field of three dim words was higher if the bright word happened also to be a novel singleton than if it were one of three familiar words. Thus, even though novel singletons were irrelevant in the task used by Diliberto et al. (1997), attention appears to have been drawn to them automatically.

\section{ALTERNATIVE INTERPRETATIONS OF NOVEL POPOUT}

We now consider how our findings and prior findings bear on three specific interpretations of novel popout that have been suggested in the literature. In particular, we consider the two main alternatives to an attention-capture interpretation of novel popout suggested by Christie and Klein (1996) and then summarize the mismatch theory of novel popout developed by Johnston and Hawley (1994).

\section{Processing Load}

The first possibility suggested by Christie and Klein (1996) is that novel popout is due to processing load or difficulty. The idea is that processing load is lower for familiar items than for novel items and that this is why localization performance increased with the ratio of familiar to novel items in the arrays, being poorest for all-novel arrays, best for all-familiar arrays, and in between for one-novel arrays. Although this account may be considered to be consistent with between-array novel popout and familiar sink-in effects (but see Johnston \& Schwarting, 1997), it does not account for the within-array advantage of novel singletons over familiar field items. Christie and Klein responded to this possible drawback by discounting the earlier observations of within-array popout, attributing them to a bias to search for novel singletons (because of a disproportionate rate of probes for novel singletons). However, although this bias may have been present in some of the earlier studies of novel popout, it was precluded in several subsequent studies, including the present one, and reliable within-array novel popout was still observed (e.g., Diliberto et al., 1998; Johnston \& Schwarting, 1997).

Our ERP data pose an additional challenge to the processing load interpretation. Although it might be claimed that N400 increases with processing load, perhaps accounting for the observed increase in N400 with the number of novel items in the arrays, this does not explain either the early onset of the $\mathrm{N} 400$ for one-novel arrays or the N400 contingencies observed in the critical one-novel arrays. Specifically, these arrays elicited larger N400s only when the subjects wound up either correctly localizing the novel singletons or incorrectly localizing the familiar field words, even though the processing load for these arrays should have been independent of subsequent response to the probes. Finally, the processing load interpretation does not account for the observation of Diliberto et al. (1997) that accuracy of localization of the brighter one of four words is enhanced if the word happens also to be novel, suggesting that novel singletons capture attention.

\section{Perceptual Trouble Spot}

A second nonattentional account of novel popout offered by Christie and Klein (1996) is an extension of the trouble-spot hypothesis originally suggested by Johnston et al. (1990). Johnston et al. suggested that the novel singletons in one-novel arrays might be represented perceptually as a localized trouble spot in a fluently unfolding perceptual field, and attention might be drawn to the trouble spot. Christie and Klein borrowed the notion of a novel singleton being represented as a perceptual trouble spot but dropped the idea of attention being drawn to this trouble spot. They suggested that subjects might simply adopt a strategy of localizing novel probes to the perceived trouble spots and familiar probes by random assignment to the other locations. In its pure form, such a strategy would result in localization accuracies of $100 \%$ for novel singletons and 33\% for their familiar companions. Although such a strategy, appropriately massaged to fit the observed localization accuracies, might account for within-array novel popout, it would have difficulty with between-array familiar sink-in. Since there would be no trouble spots in all-familiar arrays, sole reliance on the trouble-spot strategy would render localization accuracy at chance level, or $25 \%$, and yield between-array familiar popout rather than the observed sink-in.

Moreover, there is considerable evidence that word identities and not just trouble spots are extracted from onenovel arrays. For example, Johnston et al. (1990; see also Johnston \& Farah, 1986) reported within-array novel popout using an identification task in which subjects were given a location probe and asked to report the identity of the word that had appeared at that location. A troublespot strategy would not serve such a word identification task and could not account for the observed within-array popout. ${ }^{2}$ In addition, because $\mathrm{N} 400$ is, as noted above, an index of word-identity processing, its association with novel popout in the present study indicates that the subjects processed the identities of the novel singletons that they were able to correctly localize.

Finally, if a novel singleton does create a trouble spot in the unfolding perceptual array, then the evidence is that this trouble spot is not just used as a retrieval cue but actually draws attention. For example, the observed contingencies of $\mathrm{N} 400$ on localization accuracy for the one-novel 
arrays, along with the observed between-array familiar sink-in effect on localization accuracy, show that the novel singletons were processed at the expense of the familiar items. The brightness localization data of Diliberto et al. (1997) offer additional evidence for the attentioncapturing power of novel singletons. Thus, an interpretation that appeals to a trouble-spot strategy must also assume that the trouble spot is processed rapidly, at the expense of the familiar items in the display, and that some identity information is extracted from the trouble spot.

\section{Mismatch Theory}

Johnston and Hawley (1994) developed a network model of novel popout. In its simplest form, depicted in Figure 5, mismatch theory is a two-tiered network of nodes. The lower tier represents the physical features of the inputs, and the upper tier represents their conceptual features. The lower nodes are interconnected by hardwired lateral inhibitory links, and the upper nodes are interconnected by acquired excitatory links. The two tiers are themselves interconnected by bottom-up excitatory links and top-down inhibitory links. The latter links constitute the key feature of mismatch theory, the one that most distinguishes it from interactive-activation theories of perceptual processing (e.g., McClelland \& Rumelhart, 1981). The initial bottom-up processing of a one-novel array launches an intense spreading of activation across the conceptual nodes representing the familiar items relative to a much more modest activation of the conceptual node representing the novel singleton. However, the higher excitation of the conceptual nodes for the familiar items relative to the novel singleton ricochets a proportionately greater amount of top-down inhibition of the physicalfeature nodes for these items. Because of the suppressed lower tier processing of the familiar items, there is a commensurate reduction in the lateral inhibition converging onto the feature node for the novel singleton. This release from lateral inhibition yields an increase in the bottomup activation of the conceptual node for the novel singleton, contributing to novel popout. In turn, the more highly

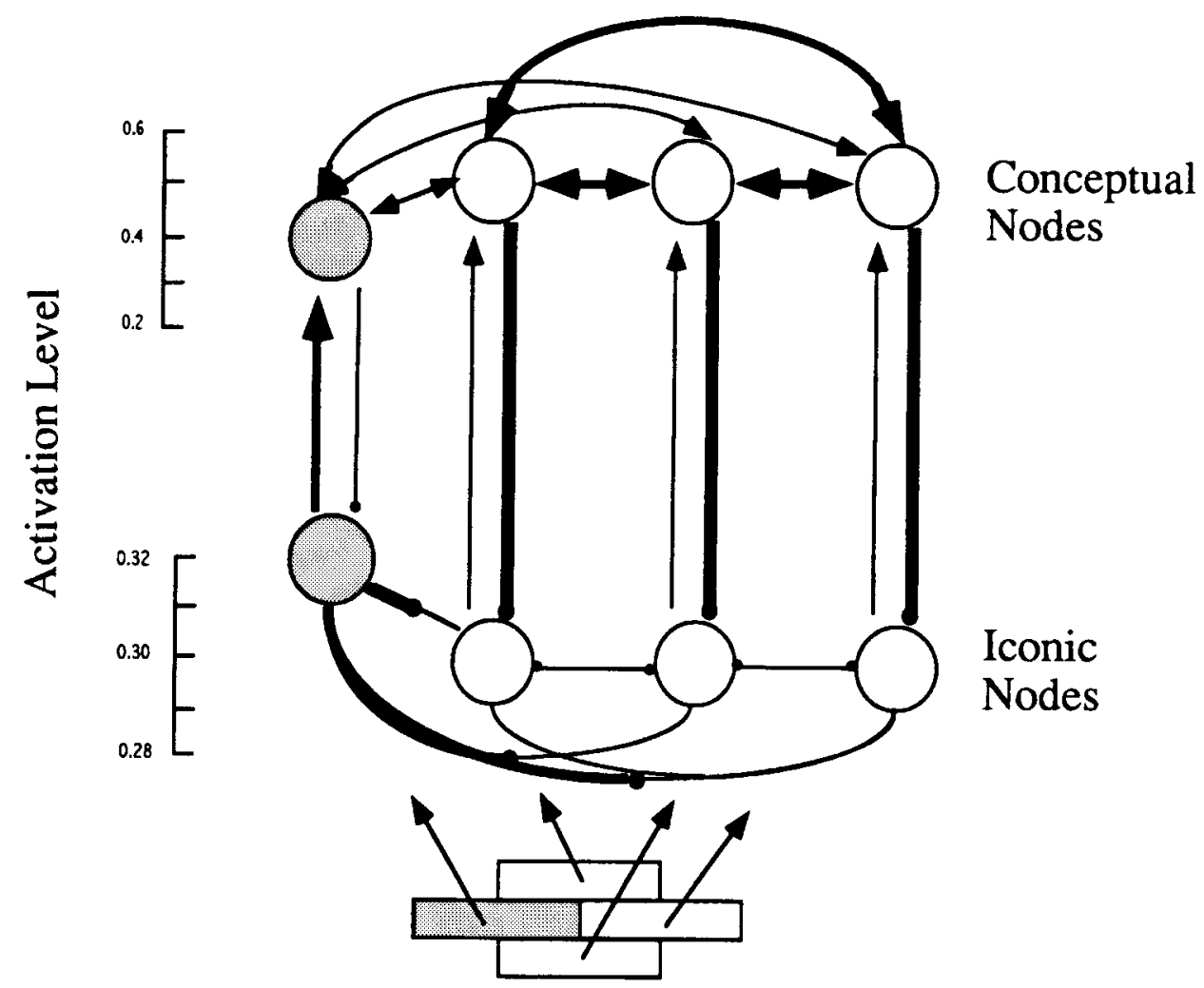

Figure 5. Simplified depiction of how mismatch theory responds to an array consisting of three expected objects (nonshaded) and one unexpected object (shaded). Activation levels are based on actual simulations performed by Johnston and Hawley (1994). Connections terminating in arrows are excitatory, and those terminating in knobs are inhibitory. Thickness of a line indicates strength of a connection. Intense spreading activation of conceptual nodes for expected objects ricochets a proportional degree of top-down inhibition of the corresponding iconic nodes. This yields a reduced degree of lateral inhibition of the iconic node representing the lone unexpected object. The net result is a conceptual bias toward expected objects and a physical bias toward the unexpected object. 
active feature node for the novel singleton delivers more lateral inhibition to the feature nodes for its familiar neighbors, contributing to familiar sink-in. ${ }^{3}$

Simulation runs of mismatch theory by Johnston and Hawley (1994) produced the entire pattern of novel popout effects, including the baseline effect, between-array novel popout, between-array familiar sink-in, and withinarray novel popout. More recently, Diliberto et al. (1997, 1998) and Schwarting and Johnston (1998) have applied mismatch theory to a range of other phenomena, including the popout of categorically odd items from a background of categorically homogeneous items and the popout of primed items from a background of nonprimed items. Thus, although mismatch theory has not yet evolved into a general theory of perception and attention, it has several advantages over alternative interpretations of novel popout. It is computationally explicit, it accommodates the full pattern of novel popout effects rather than just selected portions of it, and it is applicable to effects other than the ones it was originally designed to explain. In addition, it may be noted that subjective phenomena, such as attention in general and attention capture in particular, are emergent phenomena of mismatch theory. No appeal is made to an attention mechanism, search mechanism, central processor, executive, or other intelligent homunculus that systematically searches external arrays and can be captured by some of their contents.

Finally, the ERP data are consistent with mismatch theory. According to mismatch theory novel popout is due to differences in the initial processing of the attention array. The differences in the N400 elicited during the processing of the attention array and the absence of differences elicited by the probe array support mismatch theory. In addition, the ERP data provide converging evidence that novel singletons were processed at the expense of familiar items, as proposed by mismatch theory.

In summary, our ERP data converge with prior findings to suggest that the dynamics underlying novel popout arise early in processing, that the selective processing of the novel singleton is relatively automatic, and that processing of familiar items ordinarily suffers from the presentation of a novel singleton in the display. Taken together, these data are most consistent with an attention-based interpretation of novel popout, such as mismatch theory, in which a novel singleton in an array of inputs rapidly begins to undergo selective perceptual processing at the expense of its familiar neighbors.

\section{REFERENCES}

BENTIN. S. (1987). Event-related potentials, semantic processes, and expectancy factors in word recognition. Brain \& Language, 31, 308-327. Bentin, S., \& McCarthy, G. (1994). The effects of immediate stimulus repetition on reaction time and event-related potentials in tasks of different complexity. Journal of Experimental Psychology: Learning, Memory, \& Cognition, 20, 130-149.

Christie, J., \& Kl.EIN, R. (1996). Assessing the evidence for novel popout. Journal of Experimental Psychologv: General. 125, 201-207.

Diliberto, K. A., Altarriba, J., \& Neil.i., W. T. (1997). Novel popout and brightness discrimination: Attention as "cause " or "effect." Manuscript submitted for publication.
Diliberto, K. A., Altarriba, J., \& Neill, W. T. (1998). Novel popout without novelty. Memory \& Cognition, 26, 429.434.

Donchin. E., Ritter, W., \& McCallum, C. (1978). Cognitive psychophysiology: The endogenous components of the ERP. In E. Callaway, P. Tueting, \& S. Koslow (Eds.), Brain event-related potentials in man (pp. 371-387). New York: Academic Press.

Fabiani, M., Gratton, G., Karis, D., \& Donchin, E. (1988). The definition, identification, and reliability of measurement of the P300 component of the event-related brain potential. In P. K. Ackles, J. R. Jennings, \& M. G. Coles (Eds.), Advances in psychophysiology: Vol. 2 (pp. 1-78). Guilford, CT: JAI Press.

Gratton, G., Coles, M. G. H., \& Donchin, E. (1983). A new method for off-line removal of ocular artifact. Electroencephalography \& Clinical Neurophysiology, 55, 486-484.

HaWLey, K. J., JohnSTON, W. A., \& FARnham, J. M. (1993, May). Mismatch theory of novel popout: A computational model. Paper presented at the Third West Coast Attention Conference, Eugene, OR.

Millyard, S. A.. Mangun, G. R., WoldorfF, M. G., \& Luck, S. J. (1995). Neural systems mediating selective attention. In M. S. Gazzaniga (Ed.), The cognitive neurosciences (pp. 665-681). Cambridge, MA: MIT Press.

JASPER, H. H. (1958). The ten-twenty electrode system of the International Federation. Electroencephalography \& Clinical Neurophysiology, 10, 371-375.

Johnston, W. A., \& Farah, M. J. (1986, November). Role of environmental familiarity in selective attention. Paper presented at the annual meeting of the Psychonomic Society, New Orleans.

Johnston, W. A., \& HaWley. K. J. (1994). Perceptual inhibition of expected inputs: The key that opens closed minds. Psychonomic Bulletin \& Review, 1, 56-72.

Johnston. W. A., Hawley, K, J., \& Farnham, J. (1993). Novel popout: Empirical boundaries and a tentative theory. Journal of Experimental Psychology: Human Perception \& Performance, 19, 140-153.

Johnston, W. A., Hawley, K. J., Plewe, S. H., Ellott, J. M. G., \& DEWiTT, M. J. (1990). Attention capture by novel stimuli. Journal of Experimental Psychology: General, 119, 397-411.

Johnston, W. A., \& Schwarting, I. S. (1997). Novel popout: An enigma for conventional theories of attention. Journal of Experimental Psychology: Human Perception \& Performance, 23, 622-631.

Johnston, W. A., Schwarting, I. S., \& Hawley, K. J. (1996). Novel popout, perceptual inhibition, and the stability/plasticity dilemma. In A. F. Kramer, M. Coles, \& G. D. Logan (Eds.), Converging operations in the study of visual selective attention. Washington, DC: APA.

KuČERA, H., \& FrANCIS, W. N. (1967). Computational analysis of present-day American English, Providence, RI: Brown University Press.

Kutas, M., McCarthy, G., \& Donchin. E. (1977). Augmenting mental chronometry: The $\mathrm{P} 300$ as a measure of stimulus evaluation time. Science, 197, 792-795.

Magliero, A., Bashore, T. R., Coles, M. G. H., \& Donchin, E. (1984). On the dependence of $\mathrm{P} 300$ latency on stimulus evaluation processes. Psychophysiology, 21, 171-186.

MCCarthy, G., \& Donchin, E. (1981). A metric for thought: A comparison of $\mathrm{P} 300$ latency and reaction time. Science, 211, 77-80.

MCClelland, J. L., \& Rumelhart, D. E. (1981). An interactive activation model of context effects in letter perception: Part 1. An account of basic findings. Psychological Review, 88, 375-407.

NAGY, M. E., \& RUGG, M. F. (1989). Modulation of event-related potentials by word repetition: The effects of inter-item lag. Psychophysiology, 26, $431-436$

RUGG, M. D. (1985). The effects of semantic priming and word repetition on event-related potentials. Psychophysiology, 22, 642-647.

SCHWARTING, I. S., \& JOHNSTON, W. A. (1998). Spontaneous attention to primed and nonprimed inputs. Psychonomic Bulletin \& Review, 5, 295-299.

\section{NOTES}

1. Christie and Klein (1996) also made a footnoted reference to a serial search alternative to an attention-capture interpretation of novel popout that they attributed to J. Theeuwes. This alternative was specifically tested and rejected by Johnston and Schwarting (1997). Another 
problem with the serial search hypothesis is that the detection of the novel singleton, as indexed by the $\mathrm{N} 400$, became statistically reliable before the detection of novelty in all-novel arrays. This should never be able to happen according to the serial search hypothesis. Note that, according to the serial search hypothesis, the first (and only) words to be processed in all-novel arrays are novel, whereas the novel item would be processed first in one-novel arrays only one out of four times. Thus, the N400 data provide evidence against the serial search hypothesis.

2. Christie and Klein (1996) attempted to account for these word identification effects by assuming that perceptual trouble spots and word identities are encoded separately but not conjoined. Given a trouble-spot location as a cue, observers could appropriately guess that the novel word appeared at that location. Although this might account for novel popout effects on word identification, it would suffer the same drawback as the trouble-spot interpretation of localization effects of predicting between-array familiar popout rather than the observed sinkin (i.e., chance identification accuracy for familiar words using this strategy would be $33 \%$ in the one-novel condition and only $25 \%$ in the all-familiar condition).

3. Other dynamics of mismatch theory appear to contribute to novel popout and familiar sink-in, including a reduction in conceptual spreading of activation across the three familiar items of one-novel arrays relative to the four familiar items of all-familiar arrays.

(Manuscript received February 27, 1998; revision accepted for publication April 6, 1999.) 